\title{
Analisis Sensitivitas pada Model Matematika Transmisi Pengguna Narkoba dengan Faktor Edukasi
}

\author{
Resmawan, Anissa Dwi Wijayanti, Lailany Yahya, Agusyarif Rezka Nuha
}

Jurusan Matematika, Fakultas MIPA, Universitas Negeri Gorontalo, Jl. Prof. Dr. Ing. B. J. Habibie, Moutong, Tilongkabila, Kabupaten Bone Bolango Gorontalo 96119

E-mail: resmawan@ung.ac.id, anissadwiwijayanti@gmail.com, lailany.yahya@ung.ac.id, agusyarif@ung.ac.id

\begin{abstract}
Abstrak
Dalam artikel ini dibahas model matematika penyebaran pengguna narkoba tipe SURS. Pengembangan model dilakukan dengan penambahan faktor edukasi pada setiap kelas populasi. Selanjutnya dilakukan konstruksi angka reproduksi dasar $\left(R_{0}\right)$ untuk memodelkan nilai ambang batas penyebaran pengguna narkoba dalam suatu populasi. Angka reproduksi dasar ditentukan dengan menggunakan pendekatan Matriks Next Generation. Langkah selanjutnya dilakukan analisis sensitivitas untuk menentukan parameter yang paling berpengaruh pada terjadinya penyebaran pengguna narkoba. Berdasarkan hasil analisis, parameter $\beta$ dan $\omega_{2}$ menunjukkan indeks sensitivitas yang paling dominan terhadap angka reproduksi dasar. Pada bagian akhir artikel ini dilakukan simulasi numerik untuk menunjukan pengaruh perubahan parameter pada jumlah populasi pengguna narkoba.

Kata kunci: Analisis Sensitivitas; Model Matematika; Pengguna Narkoba; Edukasi; Angka Reproduksi Dasar.
\end{abstract}

\begin{abstract}
This article discusses the mathematical model of SURS type drug users spread. Model development by adding educational factors to each population class. Furthermore, the basic reproduction number $\left(R_{0}\right)$ is constructed to model the threshold value of the spread of drug addicts. The basic reproduction number is determined by using a Next Generation Matrix approach. The next step is to do a sensitivity analysis to determine the parameters that most influence the spread of drug addicts. Based on the analysis results, the parameters $\beta$ and $\omega_{2}$ indicate the most dominant sensitivity index to the basic reproduction numbers. At the end of this article, a simulation is carried out to show the effect of changing parameters on the population of drug addicts.
\end{abstract}

Keywords: Sensitivity Analysis; Mathematical Model; Drug Addicts; Education; Basic Reproduction Number.

2010 Mathematics Subject Classification: 93A30

Submitted: 2020-07-24, Revision: 2020-10-27 ; Accepted: 2020-10-30. 


\section{Pendahuluan}

Undang-Undang Republik Indonesia Nomor 35 Tahun 2009 Tentang Narkotika [1] menjelaskan bahwa narkotika adalah zat atau obat yang berasal dari tanaman atau bukan tanaman, baik sintetis maupun semisintetis, yang dapat menyebabkan penurunan atau perubahan kesadaran, hilangnya rasa, mengurangi sampai menghilangkan rasa nyeri, dan dapat menimbulkan ketergantungan. Hasil penelitian Badan Narkotika Nasional tahun 2017 menyatakan bahwa penyalahgunaan narkoba mencapai 3.376.115 orang pada rentang usia 10-59 tahun [2]. Kasus penyebaran pengguna narkoba dapat dirumuskan dengan pendekatan matematika melalui konsep pemodelan matematika. Pemodelan matematika merupakan cara untuk merepresentasikan persoalan kompleks ke dalam bentuk matematika berupa persamaan atau sistem persamaan [9].

Model matematika penyebaran pengguna narkoba pertama kali dibahas oleh White dan Comiskey [14] dengan membagi populasi manusia menjadi tiga kelas yaitu kelas individu yang rentan menjadi pengguna narkoba, kelas individu pengguna narkoba tidak dalam masa pengobatan, dan kelas individu pengguna narkoba dalam masa pengobatan. Penelitian lain terkait masalah narkoba dilakukan oleh Kasbawati dan Toaha [6] melalui sebuah pendekatan deterministik terhadap kasus peredaran narkoba dan penanggulangan para pecandu melalui proses rehabilitasi. Selanjutnya Husain et al., [5] menganalisis dinamika model penyebaran pengguna narkoba dengan faktor edukasi dan rehabilitasi.

Secara khusus, perhitungan angka reproduksi dasar pada konsep pemodelan matematika sangat perlu dilakukan. Angka reproduksi dasar atau basic reproduction number digunakan untuk menentukan batas antara kepunahan dan penyebaran suatu penyakit [12]. Beberapa penelitian yang membahas tentang angka reproduksi dasar diantaranya adalah penelitian yang dilakukan oleh Resmawan dan Nurwan [10] dengan menentukan angka reproduksi dasar yang menjadi tolak ukur tingkat penyebaran malaria dalam populasi. Kemudian, penelitian oleh Samsuzzoha et al., [11] yang menunjukkan bahwa pengendalian laju penularan dan tingkat pemulihan sangat penting untuk menghentikan penyebaran epidemik influenza dan penelitian oleh Hamdan dan Kilicman [4] yang melakukan analisis sensitivitas parameter terhadap angka reproduksi dasar sehingga diperoleh solusi dalam mengendalikan penularan penyakit demam berdarah.

Pada artikel ini, model matematika oleh White dan Comiskey [14] dimodifikasi dengan menambahkan kelas populasi yang telah berhenti dari pengguna narkoba $(R)$ model akan membentuk tipe $S U R S$ dan dilakukan penambahan faktor edukasi pada setiap kelas populasi sehingga menambah variabel model berupa kelas populasi rentan yang diberi edukasi $\left(S_{e}\right)$, kelas populasi pengguna narkoba yang diberi edukasi $\left(U_{e}\right)$ dan kelas populasi berhenti dari pengguna narkoba yang diberi edukasi $\left(R_{e}\right)$. Selanjutnya dilakukan konstruksi angka reproduksi dasar untuk memodelkan nilai ambang batas penyebaran pengguna narkoba dalam suatu populasi dan dilanjutkan dengan melakukan analisis sensitivitas terhadap angka reproduksi dasar sehingga diperoleh solusi dalam menekan penyebaran pengguna narkoba.

\section{Metode Penelitian}

Metode yang dilakukan pada penelitian ini adalah studi literatur dengan menelusuri dan mempelajari jurnal dan referensi yang berkaitan dengan model matematika penyebaran pengguna narkoba. Langkah-langkah yang dilakukan adalah sebagai berikut:

(1) Penelusuran jurnal dan referensi yang berkaitan dengan model matematika pada penyebaran pengguna narkoba

(2) Menentukan asumsi-asumsi yang akan digunakan untuk memodifikasi model

(3) Membentuk model matematika penyebaran pengguna narkoba dengan faktor edukasi berdasarkan asumsi-asumsi yang telah ditentukan

(4) Mencari titik kesetimbangan bebas pengguna narkoba

(5) Menentukan parameter-parameter yang mempengaruhi kelas populasi pengguna narkoba 
(6) Membentuk matriks Next Generation yang didefinisikan sebagai matriks $K$ untuk memperoleh angka reproduksi dasar

(7) Menentukan angka reproduksi dasar yang merupakan nilai eigen dominan dari matriks K

(8) Melakukan analisis sensitivitas parameter-parameter pada angka reproduksi dasar

(9) Melakukan simulasi

(10) Interpretasi dan simpulan

\section{HASIL DAN PEMBAhasan}

3.1. Model Matematika. Dalam model ini, populasi dibagi menjadi enam kelas yaitu kelas populasi rentan tanpa edukasi $S$, kelas populasi pengguna narkoba tanpa edukasi $U$, kelas populasi berhenti dari pengguna narkoba tanpa edukasi $R$, kelas populasi rentan yang diberi edukasi $S_{e}$, kelas populasi pengguna narkoba yang diberi edukasi $U_{e}$ dan kelas populasi berhenti dari pengguna narkoba yang diberi edukasi $R_{e}$.

Edukasi pada kelas populasi rentan pengguna narkoba $S_{e}$ diberikan dengan maksud untuk mencegah mereka jadi pengguna narkoba. Edukasi yang diberikan pada populasi pengguna narkoba $U_{e}$ dimaksudkan untuk memberi pemahaman dan membantu mereka berhenti dari pengguna narkoba. Adapun edukasi yang diberikan pada kelas populasi yang telah berhenti dari pengguna narkoba $R_{e}$ dimaksudkan untuk mencegah mereka kembali menjadi pengguna narkoba. Hal ini sejalan dengan fakta masih adanya mantan pengguna narkoba $\mathrm{R}$ yang berpotensi untuk kembali rentan. Asumsi ini sekaligus menghasilkan model tipe SURS pada populasi tanpa faktor edukasi. Dengan demikian, total populasi dapat dituliskan, $N=S+U+R+S_{e}+U_{e}+R_{e}$.

Secara skematis, pola penyebaran pengguna narkoba pada model ini digambarkan dalam diagram kompartemen pada Gambar 1.

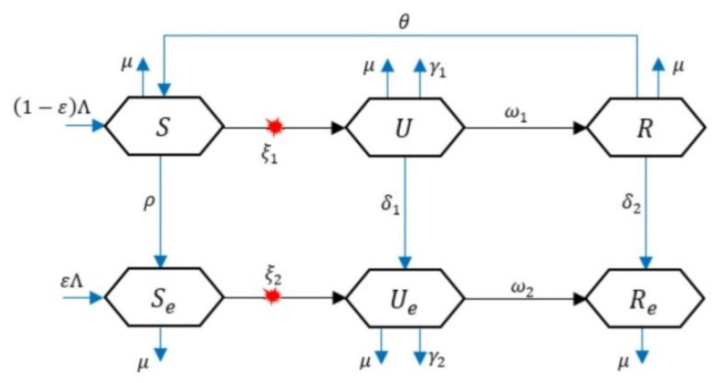

GAMBAR 1. Skema model transmisi pengguna narkoba dengan faktor edukasi

Berdasarkan Gambar 1, diperoleh model matematika transmisi pengguna narkoba dengan faktor edukasi, yang diformulasikan pada persamaan (1)

$$
\begin{aligned}
\frac{d S}{d t} & =(1-\varepsilon) \Lambda+\theta R-\xi_{1} S-(\rho+\mu) S \\
\frac{d U}{d t} & =\xi_{1} S-\left(\mu+\gamma_{1}\right) U-\left(\delta_{1}+\omega_{1}\right) U_{e} \\
\frac{d R}{d t} & =\omega_{1} U-\left(\delta_{2}+\mu\right) R-\theta R \\
\frac{d S_{e}}{d t} & =\varepsilon \Lambda+\rho S-\xi_{2} S_{e}-\mu S_{e} \\
\frac{d U_{e}}{d t} & =\xi_{2} S_{e}+\delta_{1} U-\left(\mu+\gamma_{2}\right) U_{e}-\omega_{2} U_{e} \\
\frac{d R_{e}}{d t} & =\omega_{2} U_{e}+\delta_{2} R_{e}-\mu R_{e}
\end{aligned}
$$

dengan

$$
\xi_{1}=\frac{\beta U}{N}+(1-\sigma) \frac{\beta U_{e}}{N}, \quad \xi_{2}=(1-\psi)\left[\frac{\beta U}{N}+(1-\sigma) \frac{\beta U_{e}}{N}\right]
$$


dan

$$
\frac{d N}{d t}=\Lambda-\mu N-\gamma_{1} U-\gamma_{2} U_{e}
$$

Adapun parameter-parameter yang digunakan pada persamaan (1) disajikan pada Tabel 1

TABEL 1. Keterangan parameter

\begin{tabular}{|c|c|}
\hline $\begin{array}{c}\text { Param- } \\
\text { eter }\end{array}$ & Keterangan \\
\hline$\Lambda$ & Laju rekrutmen populasi rentan progresi \\
$\varepsilon$ & Bagian dari individu rekruitmen baru dengan edukasi \\
$\rho$ & Laju edukasi terhadap populasi rentan tanpa edukasi \\
$\beta$ & Laju kontak efektif antar individu penguna dengan individu rentan \\
$\xi_{1}$ & Laju individu populasi $S$ yang berpindah ke populasi $U$ \\
$\xi_{2}$ & Laju individu populasi $S_{e}$ yang berpindah ke populasi $U_{e}$ \\
$\omega_{1}$ & Laju progresi individu $U$ berhenti dari pengguna narkoba, $U$ ke $R$ \\
$\omega_{2}$ & Laju progresi individu $U_{e}$ berhenti dari pengguna narkoba, $U_{e}$ ke $R_{e}$ \\
$\delta_{1}$ & Laju edukasi individu-individu dalam kelas $U$ \\
$\delta_{2}$ & Laju edukasi individu-individu dalam kelas $R$ \\
$\mu$ & Laju kematian secara alami \\
$\theta$ & Laju perpindahan populasi yang telah berhenti menggunakan narkoba kembali \\
& menjadi populasi rentan \\
$\gamma_{1}$ & Laju kematian yang disebabkan oleh narkoba pada individu di kelas $U$ \\
$\gamma_{2}$ & Laju kematian yang disebabkan oleh narkoba pada individu di kelas $U_{e}$ \\
$\sigma$ & Faktor reduksi dari penyebaran pengguna narkoba dengan faktor edukasi \\
$\psi$ & Laju efektifitas faktor edukasi dalam mencegah munculnya pengguna narkoba \\
& baru \\
\hline
\end{tabular}

3.2. Penentuan Titik Kesetimbangan. Untuk menentukan titik kesetimbangan pada sistem persamaan (1), dapat dicari dengan menyelesaikan persamaan tersebut dengan $\frac{d S}{N}=\frac{d U}{N}=$ $\frac{d R}{N}=\frac{d S_{e}}{N}=\frac{d U_{e}}{N}=\frac{d R_{e}}{N}=0$. Dari penyelesaian persamaan tersebut diperoleh titik kesetimbangan bebas pengguna narkoba.

$$
X_{0}\left(S, U, R, S_{e}, U_{e}, R_{e}\right)=\left(\frac{(1-\varepsilon) \Lambda}{\rho+\mu}, 0,0, \frac{\Lambda(\mu \varepsilon+\rho)}{\mu(\rho+\mu)}, 0,0\right)
$$

3.3. Perhitungan Angka Reproduksi Dasar. Berdasarkan sistem persamaan, diambil sistem persamaan yang memuat kelas populasi pengguna narkoba, yaitu

$$
\begin{aligned}
& \frac{d U}{d t}=\left(\frac{\beta U}{N}+(1-\sigma) \frac{\beta U_{e}}{N}\right) S-\left(\mu+\gamma_{1}\right) U-\left(\delta_{1}+\omega_{1}\right) U_{e} \\
& \frac{d U_{e}}{d t}=(1-\psi)\left(\frac{\beta U}{N}+(1-\sigma) \frac{\beta U_{e}}{N}\right) S_{e}+\delta_{1} U-\left(\mu+\gamma_{2}\right) U_{e}-\omega_{2} U_{e}
\end{aligned}
$$

Untuk mengetahui angka reproduksi dasar harus diketahui terlebih dahulu matriks $\phi$ yang menunjukkan parameter-parameter yang mengakibatkan bertambahnya kelas populasi pengguna narkoba dan matriks yang menunjukkan parameter-parameter yang mengakibatkan berkurangnya kelas populasi pengguna narkoba. Maka diperoleh:

$$
\begin{gathered}
\phi=\left[\begin{array}{c}
\left(\frac{\beta U}{N}+(1-\sigma) \frac{\beta U_{e}}{N}\right) S \\
(1-\psi)\left(\frac{\beta U}{N}+(1-\sigma) \frac{\beta U_{e}}{N}\right) S_{e}
\end{array}\right] \\
\varphi=\left[\begin{array}{c}
\left(\mu+\gamma_{1}+\delta_{1}+\omega_{1}\right) U_{e} \\
\left(\mu+\gamma_{2}+\omega_{2}\right) U_{e}-\delta_{1} U
\end{array}\right]
\end{gathered}
$$


Selanjutnya dibentuk matriks jacobi dari $\phi$ dan $\varphi$ yang didefinisikan sebagai matriks $F$ dan $V$ sebagai berikut:

$$
F=\left[\begin{array}{cc}
\frac{\beta S\left(S+R+S_{e}+R_{e}\right)+\sigma \beta U_{e} S}{\left(S+U+R+S_{e}+R_{e}+U_{e}\right)^{2}} & \frac{(1-\sigma) \beta S\left(S+R+S_{e}+R_{e}\right)-\sigma \beta U S}{\left(S+U+R+S_{e}+R_{e}+U_{e}\right)^{2}} \\
\frac{(1-\psi) \beta S_{e}\left(S+R+S_{e}+R_{e}\right)+(1-\psi) \sigma \beta U_{e} S_{e}}{\left(S+U+R+S_{e}+R_{e}+U_{e}\right)^{2}} & \frac{(1-\psi)(1-\sigma) \beta S_{e}\left(S+R+S_{e}+R_{e}\right)-(1-\psi) \sigma \beta U S_{e}}{\left(S+U+R+S_{e}+R_{e}+U_{e}\right)^{2}}
\end{array}\right]
$$

Selanjutnya dilakukan subtitusi titik kesetimbangan bebas pengguna narkoba yaitu pada persamaan (7) sehingga diperoleh:

$$
\begin{aligned}
& F=\left[\begin{array}{cc}
\frac{\beta \mu(1-\varepsilon)}{\rho+\mu} & \frac{\beta \mu(1-\sigma)(1-\varepsilon)}{\rho+\mu} \\
\frac{\beta(1-\psi)(\mu \varepsilon+\rho)}{\rho+\mu} & \frac{\beta(1-\psi)(1-\sigma)(\mu \varepsilon+\rho)}{\rho+\mu}
\end{array}\right] \\
& V=\left[\begin{array}{cc}
\mu+\gamma_{1}+\delta_{1}+\omega_{1} & 0 \\
-\delta_{1} & \mu+\gamma_{2}+\omega_{2}
\end{array}\right]
\end{aligned}
$$

Matriks Next Generation $(K)$ didefinisikan berdasarkan persamaan (4) dengan $K=F V^{1}$, yaitu

$$
K=\left[\begin{array}{cc}
\frac{\beta \mu(1-\varepsilon)\left(\mu+\gamma_{2}+\omega_{2}\right)+\beta \mu \delta_{1}(1-\sigma)(1-\varepsilon)}{(\rho+\mu)\left(\mu+\gamma_{1}+\delta_{1}+\omega_{1}\right)\left(\mu+\gamma_{2}+\omega_{2}\right)} & \frac{\beta \mu(1-\sigma)(1-\varepsilon)}{(\rho+\mu)\left(\mu+\gamma_{2}+\omega_{2}\right)} \\
\frac{\beta(1-\psi)(\mu \varepsilon+\rho)\left(\mu+\gamma_{2}+\omega_{2}\right)+\beta \delta_{1}(1-\psi)(1-\sigma)(\mu \varepsilon+\rho)}{(\rho+\mu)\left(\mu+\gamma_{1}+\delta_{1}+\omega_{1}\right)\left(\mu+\gamma_{2}+\omega_{2}\right)} & \frac{\beta(1-\psi)(1-\sigma)(\mu \varepsilon+\rho)}{(\rho+\mu)\left(\mu+\gamma_{2}+\omega_{2}\right)}
\end{array}\right]
$$

Berdasarkan Driessche dan Watmough [13] angka reproduksi dasar $R_{0}$ merupakan radius spektral atau nilai eigen dominan dari matriks $K$. Untuk menentukan nilai eigen dari $K$, maka akan dicari persamaan karakteristik dari matriks $K$, yaitu $\operatorname{det}(K-\lambda I)=0$ diperoleh

$\lambda^{2}-\lambda\left(\frac{\beta \mu(1-\varepsilon)\left(\mu+\gamma_{2}+\omega_{2}\right)+\beta \mu \delta_{1}(1-\sigma)(1-\varepsilon)}{(\rho+\mu)\left(\mu+\gamma_{1}+\delta_{1}+\omega_{1}\right)\left(\mu+\gamma_{2}+\omega_{2}\right)}+\frac{\beta(1-\psi)(1-\sigma)(\mu \varepsilon+\rho)}{(\rho+\mu)\left(\mu+\gamma_{2}+\omega_{2}\right)}\right)=0$

Berdasarkan persamaan karakteristik (10) diperoleh nilai eigen sebagai berikut:

$$
\begin{gathered}
\lambda_{1}=0 \\
\lambda_{2}=\frac{\beta \mu(1-\varepsilon)\left(\mu+\gamma_{2}+\omega_{2}\right)+\beta \mu \delta_{1}(1-\sigma)(1-\varepsilon)}{(\rho+\mu)\left(\mu+\gamma_{1}+\delta_{1}+\omega_{1}\right)\left(\mu+\gamma_{2}+\omega_{2}\right)}+\frac{\beta(1-\psi)(1-\sigma)(\mu \varepsilon+\rho)}{(\rho+\mu)\left(\mu+\gamma_{2}+\omega_{2}\right)}
\end{gathered}
$$

Dengan demikian, dapat ditentukan angka reproduksi dasar sebagai berikut

$$
=\frac{\beta \mu(1-\varepsilon)\left(\mu+\gamma_{2}+\omega_{2}\right)+\beta \mu \delta_{1}(1-\sigma)(1-\varepsilon)}{(\rho+\mu)\left(\mu+\gamma_{1}+\delta_{1}+\omega_{1}\right)\left(\mu+\gamma_{2}+\omega_{2}\right)}+\frac{\beta(1-\psi)(1-\sigma)(\mu \varepsilon+\rho)}{(\rho+\mu)\left(\mu+\gamma_{2}+\omega_{2}\right)}
$$

3.4. Nilai Parameter. Nilai parameter diambil berdasarkan data sekunder yang diperoleh dari berbagai referensi serta pemilihan beberapa parameter lainnya didasarkan pada asumsi. Nilai parameter yang digunakan dapat dilihat pada Tabel 2.

3.5. Analisis Sensitivitas. Pada bagian ini dilakukan analisis sensitivitas lokal untuk mengetahui parameter-parameter yang berpengaruh terhadap angka reproduksi dasar. Analisis dilakukan pada saat kondisi $R_{0}>1$ yang menunjukkan bahwa terjadinya penyebaran pengguna narkoba. Berdasarkan hal tersebut, maka perlu dilakukan analisis sensitivitas terhadap parameter-parameter untuk mengetahui upaya yang harus dilakukan agar menekan penyebaran pengguna narkoba.

Analisis sensitivitas dilakukan dengan menentukan indeks sensitivitas dari parameterparameter. Berdasarkan Chitnis et al., [3] indeks sensitivitas normalisasi dari angka reproduksi dasar didefinisikan sebagai berikut:

$$
C_{p}^{R_{0}}=\frac{\partial R_{0}}{\partial p} \times \frac{p}{R_{0}}
$$

Dimana $p$ adalah parameter-parameter yang terdapat pada angka reproduksi dasar.

Berdasarkan persamaan (12) dan nilai parameter pada Tabel 2, diperoleh indeks sensitivitas dari setiap parameter pada angka reproduksi dasar $R_{0}$ yang disajikan dalam Tabel 3 . 
TABEL 2. Nilai parameter

\begin{tabular}{|c|c|c|}
\hline Parameter & Nilai & Sumber \\
\hline$\Lambda$ & 10 & Asumsi \\
$\beta$ & 0,48 & Asumsi \\
$\mu$ & 0,02 & Li dan Ma [8] \\
$\rho$ & 0,1 & Li dan Ma [8] \\
$\varepsilon$ & 0,4 & Asumsi \\
$\sigma$ & 0,07 & Asumsi \\
$\psi$ & 0,06 & Asumsi \\
$\delta_{1}$ & 0,17 & Asumsi \\
$\delta_{2}$ & 0,47 & Asumsi \\
$\gamma_{1}$ & 0,03 & Lestari $[7]$ \\
$\gamma_{2}$ & 0,02 & Asumsi \\
$\omega_{1}$ & 0,4 & Asumsi \\
$\omega_{2}$ & 0,1 & Asumsi \\
$\theta$ & 0,08 & Asumsi \\
\hline
\end{tabular}

TABEL 3. Nilai indeks sensitivitas

\begin{tabular}{|c|c|}
\hline Parameter & Indeks sensitivitas \\
\hline$\beta$ & 1 \\
$\omega_{2}$ & $-0,69497$ \\
$\mu$ & $-0,18012$ \\
$\gamma_{2}$ & $-0,13899$ \\
$\sigma$ & $-0,07323$ \\
$\psi$ & $-0,06015$ \\
$\rho$ & 0,03927 \\
$\omega_{1}$ & $-0,03716$ \\
$\varepsilon$ & 0,03141 \\
$\delta_{1}$ & 0,01475 \\
$\gamma_{1}$ & $-0,00279$ \\
\hline
\end{tabular}

Indeks Sensitivitas dalam Tabel 3 diurutkan berdasarkan parameter dengan nilai indeks sensitivitas terbesar dan dapat disimpulkan bahwa tiap parameter memberikan pengaruh yang bervariasi terhadap $R_{0}$. Indeks sensitivitas yang bernilai positif menunjukkan adanya pengaruh perubahan nilai parameter yang berbanding lurus dengan perubahan nilai angka reproduksi dasarnya, artinya jika nilai parameter diperbesar (diperkecil) sementara parameter lainnya dibuat konstan maka akan berkontribusi pada peningkatan (penurunan) nilai $R_{0}$. Akan tetapi, indeks sensitivitas yang bernilai negatif menunjukkan adanya pengaruh perubahan nilai parameter yang berbanding terbalik dengan perubahan nilai angka reproduksi dasarnya, artinya jika nilai parameter diperbesar (diperkecil) sementara parameter lainnya dibuat konstan maka akan berkontribusi pada penurunan (peningkatan) nilai $R_{0}$.

Analisis sensitivitas menunjukkan bahwa parameter laju kontak efektif antar individu pengguna dengan individu rentan dan laju progresi pengguna narkoba yang diberi edukasi berhenti menggunakan narkoba adalah parameter yang paling sensitif terhadap perubahan angka reproduksi dasar. Indeks sensitivitas $C_{\beta}^{R_{0}}=1$ menunjukkan bahwa dengan meningkatkan nilai $\beta$ sebesar $10 \%$ maka akan meningkatkan nilai $R_{0}$ sebesar $10 \%$ dan $C_{2}^{R_{0}}=-0,69497$ menunjukkan bahwa dengan meningkatkan nilai $\omega_{2}$ sebesar $10 \%$ akan menurunkan nilai $R_{0}$ sebesar 6,9497\%.

3.6. Simulasi Numerik. Simulasi dilakukan dengan menggunakan nilai awal $S(0)=300, U(0)=$ $75, R(0)=0, S_{e}(0)=100, U_{e}(0)=25$ dan $R_{e}(0)=0$ dan nilai parameter pada Tabel 2. 
3.6.1. Simulasi Laju Kontak Efektik Antar Individu Pengguna dengan Individu Rentan pada Populasi Pengguna Narkoba. Simulasi ini dilakukan untuk menunjukkan pengaruh $\beta$ yaitu laju kontak efektif antar individu pengguna dengan individu rentan terhadap populasi pengguna narkoba dan akan ditunjukkan bahwa perubahan nilai parameter $\beta$ dapat mengubah nilai $R_{0}$. Terdapat tiga variasi nilai $\beta$ yang digunakan. Pengaruh perubahan nilai $\beta$ terhadap perubahan nilai $R_{0}$ disajikan pada Tabel 4 .

TABEL 4. Simulasi variasi perubahan $\beta$ terhadap $R_{0}$

\begin{tabular}{|c|c|}
\hline Nilai $\beta$ & Nilai $R_{0}$ \\
\hline 0,48 & 286,238 \\
0,528 & 314,862 \\
0,5808 & 346,348 \\
\hline
\end{tabular}

Berdasarkan hasil analisis sensitivitas sebelumnya, pada Tabel 4 dapat dilihat bahwa jika nilai $\beta$ ditingkatkan sebesar $10 \%$ dari nilai sebelumnya maka akan meningkatkan nilai $R_{0}$ sebesar $10 \%$ ini menunjukkan bahwa terjadinya penyebaran pengguna narkoba yang semakin meningkat. Oleh karena itu, diperlukan upaya untuk mengurangi laju kontak efektif antar individu pengguna dengan individu rentan $(\beta)$ agar nilai $R_{0}$ berkurang atau bahkan berubah nilainya sampai dengan kurang dari satu. Hasil simulasi numerik ditampilkan pada Gambar 2.
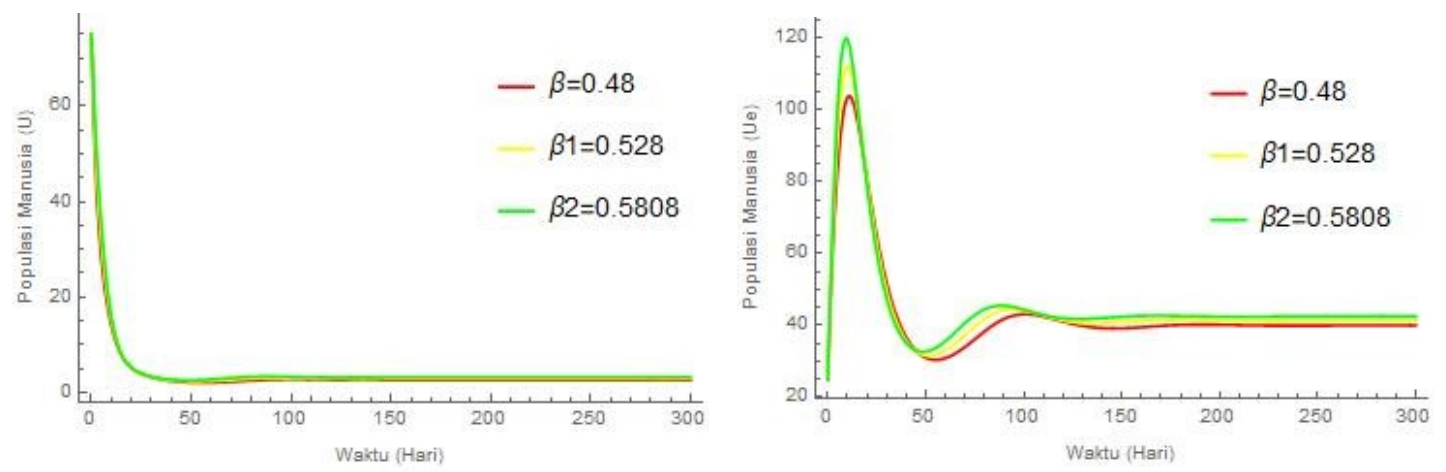

GAmbar 2. Simulasi laju kontak efektik antar individu pengguna dengan individu rentan pada populasi pengguna Narkoba $U$ dan $U_{e}$

Gambar 2 menunjukkan pengaruh laju kontak efektif antar individu pengguna dengan individu rentan terhadap populasi pengguna narkoba tanpa edukasi $(U)$ dan populasi pengguna narkoba yang diberi edukasi $\left(U_{e}\right)$. Jika nilai parameter $\beta$ diperbesar atau ditingkatkan maka akan menyebabkan semakin bertambahnya jumlah populasi pengguna narkoba $U$ dan $U_{e}$. Hal ini menunjukkan bahwa diperlukan suatu tindakan sebagai upaya untuk mengurangi laju kontak efektif antar individu pengguna dengan individu rentan agar jumlah populasi pengguna narkoba tidak bertambah bahkan berkurang hingga menuju pada kondisi bebas pengguna narkoba. Sehingga, hal tersebut dapat mengurangi laju penyebaran pengguna narkoba.

3.6.2. Simulasi Laju Progresi Pengguna Narkoba yang Diberi Edukasi Berhenti Menggunakan Narkoba Pada Populasi Pengguna Narkoba. Simulasi ini dilakukan untuk menunjukkan pengaruh $\omega_{2}$ yaitu laju progresi pengguna narkoba yang diberi edukasi berhenti menggunakan narkoba terhadap populasi pengguna narkoba ditunjukkan bahwa perubahan nilai parameter $\omega_{2}$ dapat mengubah nilai $R_{0}$. Terdapat tiga variasi nilai $\omega_{2}$ yang digunakan pada simulasi ini. Pengaruh perubahan nilai $\omega_{2}$ terhadap perubahan nilai $R_{0}$ disajikan pada Tabel 5 .

Hasil analisis sensitivitas juga dapat diamati pada Tabel 5 , jika nilai $\omega_{2}$ ditingkatkan sebesar $10 \%$ dari nilai sebelumnya maka akan menurunkan nilai $R_{0}$ sebesar $6,95 \%$. Peningkatan 
TABEL 5. Simulasi variasi perubahan $\omega_{2}$ terhadap $R_{0}$

\begin{tabular}{|c|c|}
\hline Nilai $\omega_{2}$ & Nilai $R_{0}$ \\
\hline 0,1 & 286,238 \\
0,11 & 267,672 \\
0,121 & 249,912 \\
\hline
\end{tabular}

nilai $R_{0}$ menunjukkan terjadinya penyebaran pengguna narkoba yang semakin meningkat. Sehingga, upaya yang harus dilakukan agar nilai $R_{0}$ berkurang yaitu meningkatkan laju progresi pengguna narkoba yang diberi edukasi berhenti menggunakan narkoba. Hasil simulasi numerik ditampilkan pada Gambar 3.
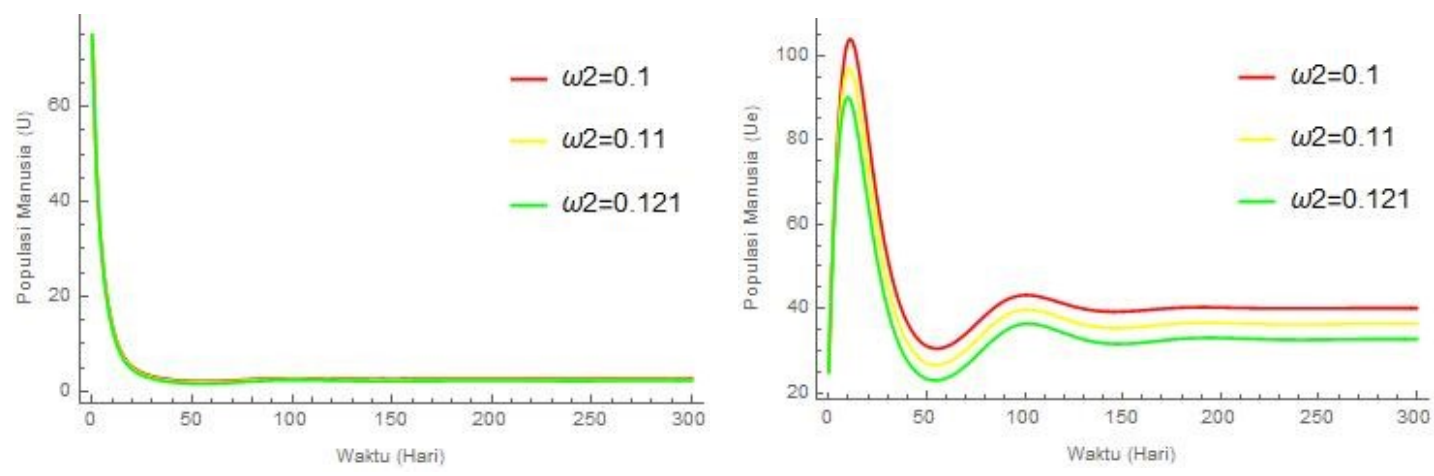

GAmbar 3. Simulasi laju progresi pengguna narkoba yang diberi edukasi berhenti menggunakan narkoba pada populasi pengguna narkoba $U$ dan $U_{e}$

Gambar 3 menunjukkan pengaruh laju progresi pengguna narkoba yang diberi edukasi berhenti menggunakan narkoba terhadap populasi pengguna narkoba tanpa edukasi $(U)$ dan populasi pengguna narkoba yang diberi edukasi $\left(U_{e}\right)$. Dari grafik pada gambar 4.3 juga dapat diketahui untuk mengurangi jumlah pengguna narkoba diperlukan upaya untuk meningkatkan laju progresi pengguna narkoba yang diberi edukasi berhenti menggunakan narkoba.

\section{SIMPULAN}

Berdasarkan hasil analisis, diperoleh rumusan angka reproduksi dasar sebagaimana yang ditulis pada persamaan (11). Selain itu, hasil analisis sensitivitas dan simulasi menunjukkan bahwa mengurangi laju kontak efektif antar individu pengguna dengan individu rentan dan meningkatkan laju progresi pengguna narkoba yang diberi edukasi berhenti menggunakan narkoba dapat mengurangi atau menekan laju penyebaran pengguna narkoba.

\section{Daftar Pustaka}

[1] 13. undang-undang republik indonesia nomor 35 tahun 2009 tentang narkotika. Lembaran Negara Republik Indonesia Tahun 2009 Nomor 143, 12 Oktober 2019. Diakses pada: 28 Desember 2019.

[2] BNN. Penggunaan narkotika di kalangan remaja meningkat. https://bnn.go.id/penggunaan-narkotika-kalangan-remaja-meningkat/. Diakses pada: 28 Desember 2019.

[3] Nakul Chitnis, James M Hyman, and Jim M Cushing. Determining important parameters in the spread of malaria through the sensitivity analysis of a mathematical model. Bulletin of mathematical biology, 70(5):1272, 2008.

[4] NI Hamdan and A Kilicman. Sensitivity analysis in a dengue fever transmission model: A fractional order system approach. In Journal of Physics: Conference Series, volume 1366, page 012048. IOP Publishing, 2019. 
[5] Moh Rizal Husain, Nurwan Nurwan, and Resmawan Resmawan. Analisis kestabilan model penyebaran pengguna narkoba dengan faktor edukasi. BAREKENG: Jurnal Ilmu Matematika dan Terapan, 14(1):069-078, 2020.

[6] Kasbawati Kasbawati and Syamsuddin Toaha. Model deterministik masalah kecanduan narkoba dengan faktor kontrol terhadap pemakai dan pengedar narkoba. Jurnal Matematika, Statistika dan Komputasi, 7(1):13-22, 2018.

[7] Riri Lestari. Pengembangan model penyebaran pengguna narkoba white-comiskey. Bogor: Tesis Program Studi Matematika Terapan Institut Pertanian Bogor, 2002.

[8] Jun Li and Mingju Ma. The analysis of a drug transmission model with family education and public health education. Infectious Disease Modelling, 3:74-84, 2018.

[9] Meksianis Zadrak Ndii. Pemodelan Matematika Dinamika Populasi Dan Penyebaran Penyakit Teori, Aplikasi, Dan Numerik. Deepublish, 2018.

[10] Resmawan Resmawan. Efektifitas vaksinasi dan pengasapan pada model epidemik transmisi penyakit malaria. Jambura Journal of Mathematics, 1(1):25-35, 2019.

[11] MD Samsuzzoha, Manmohan Singh, and David Lucy. Uncertainty and sensitivity analysis of the basic reproduction number of a vaccinated epidemic model of influenza. Applied Mathematical Modelling, 37(3):903-915, 2013.

[12] Novita Dwi Susanti. Analisis perhitungan bilangan reproduksi dasar (R_O) pada model matematika dinamika malaria host-vector. PhD thesis, Universitas Islam Negeri Maulana Malik Ibrahim, 2016.

[13] Pauline Van den Driessche and James Watmough. Reproduction numbers and subthreshold endemic equilibria for compartmental models of disease transmission. Mathematical biosciences, 180(1-2):29-48, 2002.

[14] Emma White and Catherine Comiskey. Heroin epidemics, treatment and ode modelling. Mathematical biosciences, 208(1):312-324, 2007. 
104 Resmawan dkk, JMI Vol 16 No 2 2020, pp. 95-103,doi:10.24198/jmi.v16.n2.28804.95-103 